\title{
Long-term use of dasatinib in patients with metastatic castration-resistant prostate cancer after receiving the combination of dasatinib and docetaxel
}

\author{
This article was published in the following Dove Press journal: \\ Cancer Management and Research \\ 8 March 2013 \\ Number of times this article has been viewed
}

\author{
John C Araujo' \\ Geralyn C Trudel ${ }^{2}$ \\ Prashni Paliwal ${ }^{3}$ \\ 'Department of Genitourinary \\ Medical Oncology, Division of Cancer \\ Medicine, The University of Texas MD \\ Anderson Cancer Center, Houston, \\ TX, USA; ${ }^{2}$ Bristol-Myers Squibb, \\ Montreal, Quebec, Canada; ${ }^{3}$ Bristol- \\ Myers Squibb, Wallingford, CT, USA
}

\begin{abstract}
Dasatinib is a potent oral tyrosine kinase inhibitor which targets several kinases, including the SRC family kinases. SRC family kinases have been implicated in androgen therapy resistance that often develops in metastatic castration-resistant prostate cancer (mCRPC), which drives the need for non-androgen targeting therapies. This article describes the preclinical rationale for the use of combination dasatinib and docetaxel therapy in mCRPC, and highlights the results of a phase I-II trial in which 46 patients with $\mathrm{mCRPC}$, treated with a regimen of dasatinib and docetaxel, demonstrated improvements in bone scans, high rates of soft tissue responses, and modulation of markers of bone turnover. This brief report discusses in detail follow-up data on two patients who remain alive after $>2.5$ years on dasatinib single-agent therapy after discontinuing docetaxel treatment.
\end{abstract}

Keywords: case study, dasatinib, docetaxel, prostate cancer, targeted therapy

\section{Introduction}

Prostate cancer is the second most common malignancy worldwide, representing the sixth leading cause of cancer-related deaths in men. ${ }^{1}$ In advanced disease, androgen deprivation therapy results in decreased serum prostate-specific antigen (PSA) and tumor regression in the majority of patients. ${ }^{2}$ However, while prostate cancer is an androgen-dependent malignancy, over time resistance occurs through androgenindependent processes, one of which is the SRC family kinase signaling pathway. Targeting androgen receptor (AR)-independent processes and resensitizing the AR to alternate therapy are potential therapeutic approaches for metastatic castration-resistant prostate cancer (mCRPC). Resistance is thought to derive from many mechanisms: the AR can become transactivated in a low-androgen environment through amplification and mutation of the receptor, crosstalk with other signaling pathways, and altered regulation by coregulatory proteins. ${ }^{3}$ Importantly, SRC kinase has been implicated in AR crosstalk. Upon ligand binding, the AR binds and quickly activates SRC kinase and downstream events. In turn, SRC kinase can tyrosine phosphorylate the AR, augmenting its transcriptional activity. ${ }^{4}$ Additionally, SRC kinase activity has been found to be upregulated in a number of preclinical models of CRPC; ;,6 as such, a potentially effective strategy to inhibit prostate cancer growth and metastasis may be to target SRC kinase.

Dasatinib (SPRYCEL ${ }^{\circledR}$, Bristol-Myers Squibb, Princeton, NJ, USA) is a potent oral tyrosine kinase inhibitor that has been approved for the treatment of Philadelphia chromosome-positive $(\mathrm{Ph}+)$ chronic myeloid leukemia (CML). ${ }^{7}$ Dasatinib inhibits
Correspondence: John C Araujo Department of Genitourinary Medical Oncology, Division of Cancer Medicine, The University of Texas MD Anderson Cancer Center, Houston, TX, USA

$\mathrm{Tel}+\mathrm{I} 7135637203$

Email johna@mdanderson.org 
several tyrosine kinases, including SRC kinase, which has been shown in preclinical studies to have synergistic activity with docetaxel, ${ }^{8}$ antimetastatic properties, ${ }^{9,10}$ and potent inhibition of osteoclast function. ${ }^{11}$

In an open-label, phase I-II study, 46 patients with mCRPC treated with a combination of dasatinib and docetaxel experienced a 60\% Response Evaluation Criteria In Solid Tumors (RECIST) response rate, 77\% disease control rate, as well as stabilization of bone metastases accompanied by decreases in bone marker turnover ${ }^{12}$ (Figure 1). In addition, $80 \%$ of patients experienced a PSA decrease, including $57 \%$ with a confirmed PSA response (sustained $\geq 50 \%$ decline for $\geq 6$ weeks). ${ }^{12}$ These findings provided the basis for the initiation of the phase III READY trial, a randomized, double-blind, placebo-controlled study comparing the efficacy and safety of dasatinib and docetaxel/prednisone combination versus the current standard of care of docetaxel/ prednisone plus placebo in men with mCRPC (Clinicaltrials. gov NCT00744497).
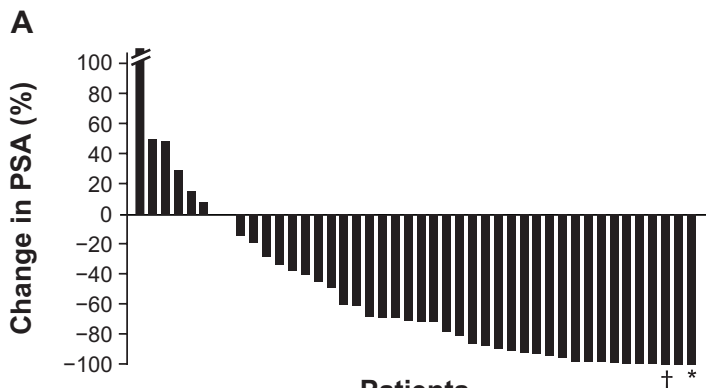

Patients

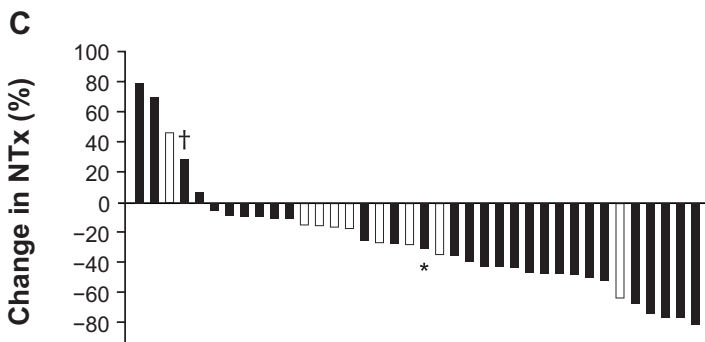

Patients
Of note in the phase I-II study, patients could continue to receive dasatinib after discontinuing docetaxel, ${ }^{12}$ with the concept that the antimetastatic properties of dasatinib and its inhibition of osteoclasts would be able to further suppress the disease, and subsequently give prolonged responses by delaying progression. Overall, $61 \%$ of patients continued to receive dasatinib until progression. ${ }^{12}$ Furthermore, after more than 2.5 years of discontinuing docetaxel, two patients with mCRPC continue to be treated with single-agent dasatinib with no evidence of progression by radiographic studies. In this article, we provide a detailed report of these two cases, examining their clinical results in an effort to learn more about the potential role of dasatinib in MCRPC.

\section{Methods}

The methodology of the open-label phase I-II study has been described previously. ${ }^{12}$ Adult males with metastatic prostate cancer who had progressed despite castrate levels of serum testosterone ( $\leq 50 \mathrm{ng} / \mathrm{dL}$ ) were eligible for enrollment.

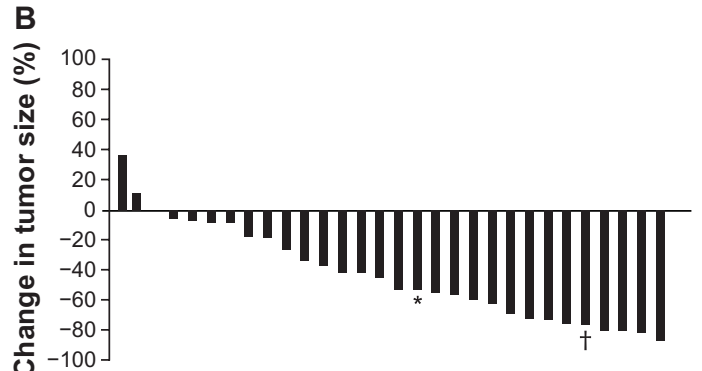

Patients

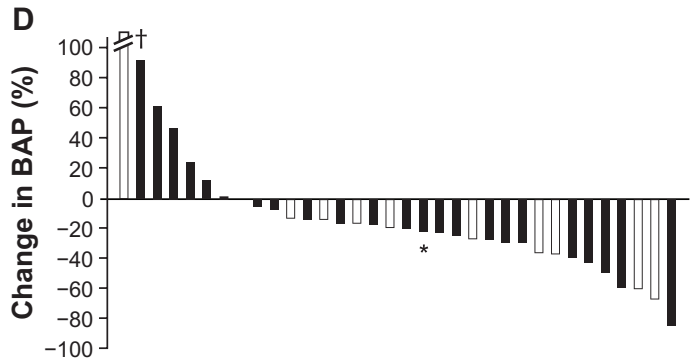

Patients

Figure I Waterfall plots show maximal percentage changes from baseline in individual patients with mCRPC treated with combination dasatinib and docetaxel in an openlabel, phase I-II study: (A) PSA; ${ }^{\text {(B) }}$ Tumor size; (C) NTx; (D) BAP. ${ }^{\text {b }}$

Notes: In panels $C$ and D, patients who were receiving ongoing bisphosphonate therapy are shown in white bars. Values for changes in PSA, tumor size, NTx, and BAP that correlate to patient I have been denoted with an asterisk $(*)$, while those for patient 2 have been denoted with a dagger $\left({ }^{\dagger}\right)$. Both patients I and 2 had striking PSA decreases, indicating that the combination of dasatinib and docetaxel affected the prostate cancer epithelial cells (A). Compared to the entire population of patients, they fell on the greatest decreases in PSA. This was also reflected in a decrease in tumor size and volume of disease (B). Patient I, whose disease was predominately in bone, had a decrease in bone turnover markers (NTx and BAP, C and D, respectively), whereas patient 2, whose disease was solely detected in lymph nodes, had an increase in both bone markers. When comparing bone markers alone, as compared to other patients within the study, patient I fell within bone marker turnover median as indicated in the waterfall plots. He demonstrated one of the most durable responses, and, therefore, a decrease in PSA combined with decrease in bone turnover markers in patients with metastatic bone disease might portend a better outcome. On the other hand, in patients with soft tissue disease (lymph nodes alone, patient 2), a decrease in PSA combined with increase in these markers may lead to an improved outcome and survival advantage, which needs to be investigated further. ${ }^{\mathrm{a}}$ The best percent change from baseline for subject 86035 (left-most whisker) was 205.7 and has been truncated on the graph shown in panel A; be best percent change from baseline for subject 86037 (left-most whisker) was 426.540 , and has been truncated on the graph shown in panel D.

Plots redrawn with permission from John Wiley and Sons, Copyright 201 I American Cancer Society. ${ }^{12}$

Abbreviations: BAP, bone alkaline phosphatase; mCRPC, metastatic castration-resistant prostate cancer; NTx, urinary N-telopeptide; PSA, prostate-specific antigen. 


\section{Dosing}

In phase I of the study, patients received escalating doses of docetaxel (administered intravenously every 21 days from day 1 of cycle 1 with oral prednisone $5 \mathrm{mg}$ twice daily) and dasatinib (administered once daily beginning on day 3 of cycle 1) for a minimum of 6 cycles, except in cases of disease progression or significant toxicity. Doses of dasatinib $(\mathrm{mg}) /$ docetaxel $\left(\mathrm{mg} / \mathrm{m}^{2}\right)$ included the following, 50/60, $50 / 75,70 / 75,100 / 75$, and 120/75. After 6 cycles of treatment, patients could discontinue docetaxel and continue to receive single-agent dasatinib until disease progression. In phase II of the study, patients received $100 \mathrm{mg}$ of dasatinib and $75 \mathrm{mg} / \mathrm{m}^{2}$ of docetaxel and their regimen could be dosereduced for either drug to $70 \mathrm{mg}$ of dasatinib and $60 \mathrm{mg} / \mathrm{m}^{2}$ of docetaxel due to toxicity.

\section{Assessments}

Bone scans were performed within 28 days before treatment and every 6 weeks after initiating docetaxel. Computed tomography (CT) scans were also obtained at this time interval. Blood samples were assessed for PSA (every 3 weeks) and bone alkaline phosphatase (BAP), a marker of osteoblast differentiation (measured before treatment and at least once after cycle 1 while patients were receiving combination docetaxel and dasatinib treatment). Urine samples were also assessed for levels of urinary N-telopeptide (NTx), a marker of osteoclast activity, before treatment and at least once after cycle 1 while patients were receiving combination docetaxel and dasatinib treatment.

\section{Results}

Of the 46 patients enrolled in the study, 28 (61\%) were treated with single-agent dasatinib for a median of 2.9 months up to data capture after discontinuing docetaxel. ${ }^{12}$ Twenty-four of these patients continued dasatinib treatment for $>42$ days after discontinuation of concomitant docetaxel. Thirteen patients were treated with dasatinib for less than 6 months and eleven received treatment for more than 6 months. Of these later eleven patients, seven received treatment for more than 1 year, five patients for more than 2 years, and one patient for more than 3 years. At the time of data analysis, six of the 24 patients demonstrated no progression, with stable disease for a range of 3.4 to 11.7 months after the last docetaxel dose. ${ }^{12}$

As of September 2012, two of the 24 patients remain alive after more than 2.5 years and 3 years of single-agent dasatinib. One of these two patients presented with multifocal bone disease after rapidly progressing through androgen therapy; the second patient presented with lymph node metastasis following progression on androgen therapy.

\section{Case study: patient I}

A male patient aged 74 years at the start of the trial, with a past medical history of chronic tobacco use and chronic obstructive pulmonary disease (COPD), presented with right flank pain and multifocal osseous metastasis in his ribs, spine, pelvic bones, right scapula, and right proximal femur in August 2007 at diagnosis. Prostate biopsies revealed a Gleason $8(4+4)$ prostate adenocarcinoma with stage T2 disease and PSA level of $969 \mathrm{ng} / \mathrm{mL}$. Complete androgen blockade of bicalutamide and a luteinizing hormone-releasing hormone analogue were initiated in September 2007, with PSA levels decreasing to a nadir of $1.5 \mathrm{ng} / \mathrm{mL}$. In August 2008, the patient presented with a rising PSA. Bicalutamide was withdrawn and his PSA continued to rise in September 2008 and, though the patient was asymptomatic, progression of disease was revealed on bone scan (Figure 2A). Approximately 14 months after diagnosis, in October 2008, the patient was enrolled in the previously described open-label, phase I-II study ${ }^{12}$ and received $100 \mathrm{mg}$
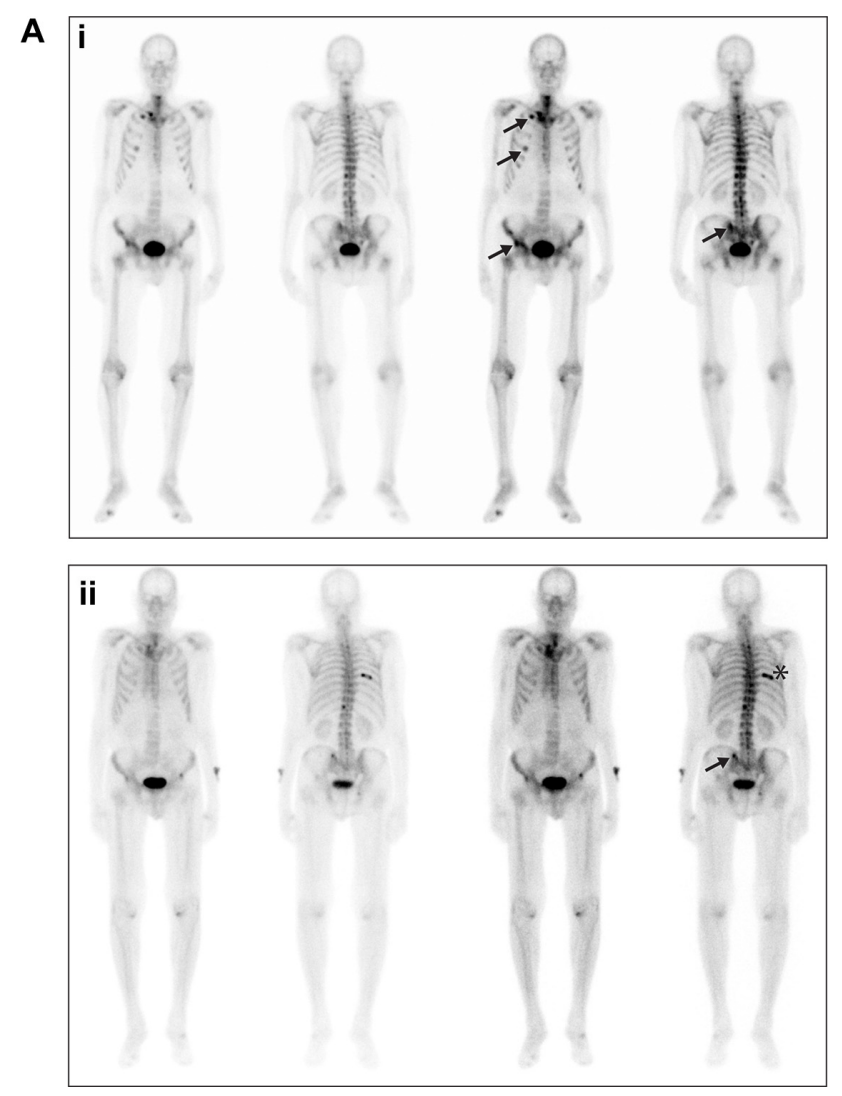

Figure 2A Bone scans from patient I, taken in (i) September 2008 and (ii) June 2012.

Notes: Arrows in both panels indicate sites of metastases; the asterisk in the lower panel indicates a site of trauma. 

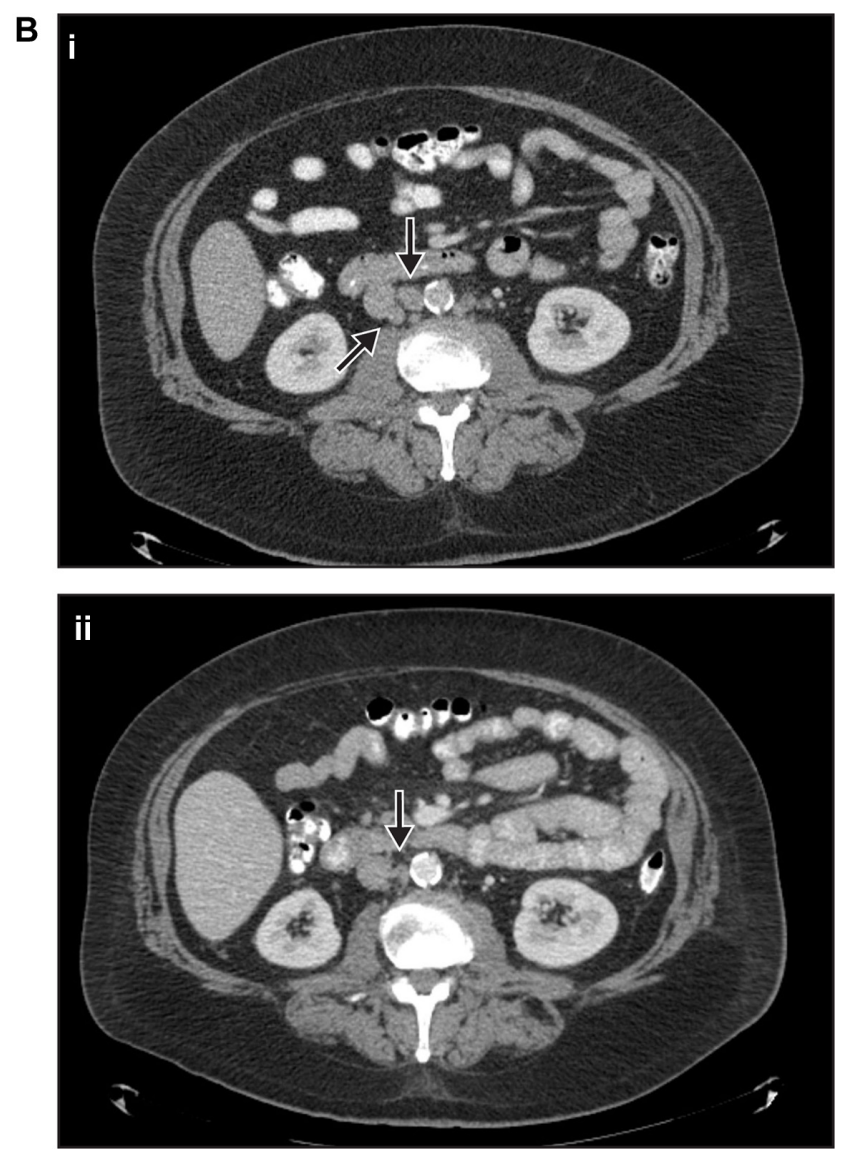

Figure 2B CT scans from patient 2 taken in (i) September 2008 and (ii) July 2012. Note: Arrows in both panels indicate sites of metastases. Abbreviation: CT, computed tomography.

daily of dasatinib for 336 days and $75 \mathrm{mg} / \mathrm{m}^{2}$ of docetaxel, for a total of 16 cycles. Docetaxel was delayed 3 times during the course of treatment; in cycles 3,5 , and 7 . The first delay was due to a COPD exacerbation in combination with a suspected upper respiratory infection (URI), delaying cycle 3 of treatment. A viral URI delayed cycle 5, and COPD exacerbation delayed cycle 7 of treatment. Each resulted in 1-week delays of docetaxel infusion. Of note, the patient was a long-time smoker ( $>120$ pack-year history) and continued to smoke throughout the study. After 16 cycles, docetaxel was discontinued.

Baseline study assessments prior to initiating dasatinib and docetaxel treatment (day 0 ), at docetaxel discontinuation (day 341), and at the last assessment on single-agent dasatinib therapy (day 1319) are summarized in Table 1.

\section{Case study: patient 2}

A male patient aged 53 years with a past medical history of hypertension, hypercholesterolemia, and coronary artery disease (with cardiac stents implanted in 2008), was diagnosed with a Gleason $7(3+4)$ prostate adenocarcinoma with focal ductal features and stage T2 disease in April 2003. Six months postsurgery, the patient's PSA was $1.0 \mathrm{ng} / \mathrm{mL}$. Following an increase in the patient's PSA level to $8.8 \mathrm{ng} / \mathrm{mL}$ in July 2004 , he was treated with androgen ablation agents leuprolide and bicalutamide; his PSA had a nadir level of $0.1 \mathrm{ng} / \mathrm{mL}$ for $<1$ year. Bicalutamide was discontinued in March 2007 and the patient was treated with ketoconazole from April 2007 until June 2007, without PSA response but with subsequent radiographic progression in the aortocaval and para-aortic regions with lymph nodes of $2 \mathrm{~cm}$ and $1.7 \mathrm{~cm}$, respectively, as well as smaller retroperitoneal lymph nodes, suggesting that the disease was becoming driven by AR-independent processes. In June 2007, the patient's lymph nodes continued to enlarge on CT scan and his PSA level rose to $8.9 \mathrm{ng} / \mathrm{mL}$, and he was continued on androgen ablation with leuprolide. In September 2008, the patient progressed, with increased lymph node size (Figure 2B) and a PSA level of $24.2 \mathrm{ng} / \mathrm{mL}$. Though asymptomatic and without any metastatic disease to bone, in October 2008, the patient was enrolled in the previously described open-label, phase I-II study ${ }^{12}$ and was treated with 10 cycles of docetaxel and continuous dasatinib. After the first cycle, the dasatinib and docetaxel doses were reduced from $100 \mathrm{mg}$ daily for dasatinib and $75 \mathrm{mg} / \mathrm{m}^{2}$ for docetaxel to $70 \mathrm{mg}$ daily for dasatinib and $60 \mathrm{mg} / \mathrm{m}^{2}$ for docetaxel, due to stomatitis and mucositis. Docetaxel treatment was discontinued 190 days following the initiation of dasatinib and docetaxel treatment because maximal PSA response was achieved.

Baseline study assessments prior to initiating dasatinib and docetaxel treatment (day 0), at docetaxel discontinuation (day 190), and at the last assessment on single-agent dasatinib (day 1373) are summarized in Table 1.

\section{Discussion}

Upon initial diagnosis with prostate cancer, androgen deprivation therapy is usually highly effective and successful in managing many patients' disease. ${ }^{2}$ Unfortunately, most patients develop resistance to androgen therapy and become castrate-resistant, ${ }^{2}$ with AR-independent pathways becoming disease drivers. Docetaxel has become the standard of care over the last 10 years ${ }^{13-15}$ because it has demonstrated improvement in overall survival by treating the underlying prostate cancer and has ameliorated pain after progression. More than 10 different combinations with docetaxel have failed in previous phase III trials; ${ }^{16-19}$ however, we continue to strive for new treatment options to target AR-independent pathways and perhaps resensitize the AR to hormonal 
Table I Assessments prior to docetaxel treatment, following docetaxel discontinuation, and at end of follow-up during single-agent dasatinib treatment

\begin{tabular}{|c|c|c|c|}
\hline & $\begin{array}{l}\text { Assessment before docetaxel } \\
\text { treatment }\end{array}$ & $\begin{array}{l}\text { Assessment at docetaxel } \\
\text { discontinuation }\end{array}$ & $\begin{array}{l}\text { Last assessment with single-agent } \\
\text { dasatinib treatment }\end{array}$ \\
\hline $\begin{array}{l}\text { Patient I } \\
\text { (74-year-old } \\
\text { male, bone } \\
\text { metastasis) }\end{array}$ & $\begin{array}{l}\text { Laboratory assessments } \\
\text { - PSA: } 29.3 \mathrm{ng} / \mathrm{mL} \\
\text { - Urinary NTx: } 8 \mathrm{I} \mathrm{nmol} \mathrm{BCE} / \mathrm{mmol} \text { creatine } \\
\text { - BAP: } 14.9 \mathrm{ng} / \mathrm{mL} \\
\text { Bone scan } \\
\text { - Multiple bone lesions (spine, pelvic bones, } \\
\text { ribs, bilateral scapula, right humerus, } \\
\text { right proximal femur) } \\
\text { Symptoms } \\
\text { - Progressive pain }\end{array}$ & $\begin{array}{l}\text { Treatment duration } \\
\text { (dasatinib + docetaxel): } 34 \text { I days }\end{array}$ & $\begin{array}{l}\text { Laboratory assessments } \\
\text { - PSA: } 0.4 \mathrm{ng} / \mathrm{mL}^{\mathrm{a}} \\
\text { - Urinary NTx: } 15 \mathrm{nmol} \mathrm{BCE} / \mathrm{mmol} \text { creatine } \\
\text { - BAP: } 6.4 \mathrm{ng} / \mathrm{mL} \\
\text { Bone scan } \\
\text { - Single bone lesion } \\
\text { Symptoms } \\
\text { - Asymptomatic } \\
\text { Treatment duration } \\
\text { (single-agent dasatinib): } 978 \text { days+ }\end{array}$ \\
\hline $\begin{array}{l}\text { Patient } 2 \\
\text { (53-year-old male, } \\
\text { lymph node } \\
\text { metastasis) }\end{array}$ & $\begin{array}{l}\text { Laboratory assessments } \\
\text { - PSA: } 28.4 \mathrm{ng} / \mathrm{mL} \\
\text { CT scan } \\
\text { - Enlarged pelvic lymph nodes }\end{array}$ & $\begin{array}{l}\text { Laboratory assessments } \\
\text { - PSA: } 0.2 \mathrm{ng} / \mathrm{mL} \text { (maximized benefit) } \\
\text { CT scan } \\
\text { - Reduced size of pelvic lymph nodes }\end{array}$ & $\begin{array}{l}\text { Laboratory assessments } \\
\text { - PSA: II.4 } \mathrm{ng} / \mathrm{mL}^{\mathrm{b}} \\
\text { Symptoms } \\
\text { - Asymptomatic } \\
\text { Treatment duration } \\
\text { (single-agent dasatinib): I } 183 \text { days+ }\end{array}$ \\
\hline
\end{tabular}

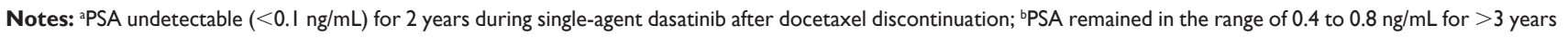
during single-agent dasatinib, including the last month of treatment, increasing to $11.4 \mathrm{ng} / \mathrm{mL}$ at the last assessment.

Abbreviations: BAP, bone alkaline phosphatase; BCE, bone collagen equivalent; CT, computed tomography; NTx, urinary N-telopeptide; PSA, prostate-specific antigen.

therapy. Here, we have explored the addition of an agent to docetaxel, which exploits multiple pathways within the prostate cancer tumor microenvironment.

Dasatinib is a potent oral tyrosine kinase inhibitor that has been approved for treatment of CML, ${ }^{7}$ aiding in the transformation of this tumor type into a chronic disease by targeting the BCR-ABL kinase. Dasatinib combined with docetaxel in mCRPC provides synergistic efficacy, which has been demonstrated both preclinically and clinically. ${ }^{8,12}$ In addition, dasatinib has been shown preclinically to have antimetastatic activity that prevents the development of new metastase $^{9,10}$ and targets the underlying bone disease by potently inhibiting osteoclasts. ${ }^{11}$

Dasatinib targets a number of different kinases, including ACK1, BCR-ABL, SRC family (SRC, LCK, YES, FYN), c-KIT, EPHA2, and PDGFR $\beta,{ }^{7}$ with SRC inhibition postulated to be the primary mechanism through which it works in mCRPC. Through directly targeting AR-independent pathways and with the potential mechanism of resensitizing $\mathrm{AR}$, dasatinib is an important new treatment being explored in $\mathrm{MCRPC}$.

Initial phase I-II study results, including a 60\% RECIST response rate, prevention of metastases with the stabilization of bone lesions, and reduction in bone turnover markers, provide some evidence of efficacy for the combination of dasatinib with docetaxel in mCRPC. ${ }^{12}$ However, long-term follow up of this study has allowed for the most intriguing part of this study to be reported: the ability of dasatinib, as a single agent, to hold the disease by preventing progression.

In the two presented cases, disease had progressed with bone or soft tissue metastases and appeared to have become resistant to androgen deprivation prior to study entry. Patient 1 , who initially presented with bone metastasis, continued to have resolution of bone metastasis after discontinuation of docetaxel, followed by stabilization and prevention of new lesions while on single-agent dasatinib. He remains asymptomatic as of September 2012. Patient 2, who presented with lymph node metastasis, was able to achieve a maximal PSA response while on dasatinib therapy after discontinuing docetaxel treatment and remains asymptomatic as of September 2012 as well.

The two cases described in this report suggest that the addition of dasatinib to docetaxel can provide meaningful clinical benefit to patients, delaying disease progression, which will hopefully translate into prolonged survival.

\section{Acknowledgments}

We wish to thank Mark A Wildgust, $\mathrm{PhD}$, for his insight in the development of this article, and Christopher Logothetis, $\mathrm{MD}$, for his critical scientific review of earlier drafts of this case report. Professional medical writing and editorial 
assistance was provided by Ami P Modi, PhD, at StemScientific, and funded by Bristol-Myers Squibb (BMS).

\section{Disclosure}

GCT and PP are BMS employees and have stock ownership in BMS. The authors report no other conflicts of interest in this work.

\section{References}

1. Ferlay J, Shin HR, Bray F, Forman D, Mathers C, Parkin DM. Estimates of worldwide burden of cancer in 2008: GLOBOCAN 2008. Int J Cancer. 2010;127(12):2893-2917.

2. Scher HI, Sawyers CL. Biology of progressive, castration-resistant prostate cancer: directed therapies targeting the androgen-receptor signaling axis. J Clin Oncol. 2005;23(32):8253-8261.

3. Lamont KR, Tindall DJ. Minireview: Alternative activation pathways for the androgen receptor in prostate cancer. Mol Endocrinol. 2011; 25(6):897-907.

4. Chen Y, Sawyers CL, Scher HI. Targeting the androgen receptor pathway in prostate cancer. Curr Opin Pharmacol. 2008;8(4):440-448.

5. Guo Z, Dai B, Jiang T, et al. Regulation of androgen receptor activity by tyrosine phosphorylation. Cancer Cell. 2006;10(4):309-319.

6. Asim M, Siddiqui IA, Hafeez BB, Baniahmad A, Mukhtar H. Src kinase potentiates androgen receptor transactivation function and invasion of androgen-independent prostate cancer C4-2 cells. Oncogene. 2008; 27(25):3596-3604.

7. Bristol-Myers Squibb Company. SPRYCEL ${ }^{\circledR}$ (Dasatinib) [Package Insert]. Princeton, NJ: Bristol-Myers Squibb Company; 2012. Available from: http://packageinserts.bms.com/pi/pi_sprycel.pdf. Accessed February 5, 2013.

8. Koreckij T, Nguyen H, Brown, Yu EY, Vessella RL, Corey E. Dasatinib inhibits the growth of prostate cancer in bone and provides additional protection from osteolysis. Br J Cancer. 2009;101(2):263-268.

9. Nam S, Kim D, Cheng JQ, et al. Action of the Src family kinase inhibitor, dasatinib (BMS-354825), on human prostate cancer cells. Cancer Res. 2005;65(20):9185-9189.
10. Park SI, Zhang J, Phillips KA, et al. Targeting SRC family kinases inhibits growth and lymph node metastases of prostate cancer in an orthotopic nude mouse model. Cancer Res. 2008;68(9):3323-3333.

11. de Vries TJ, Mullender MG, van Duin MA, et al. The Src inhibitor AZD0530 reversibly inhibits the formation and activity of human osteoclasts. Mol Cancer Res. 2009;7(4):476-488.

12. Araujo JC, Mathew P, Armstrong AJ, et al. Dasatinib combined with docetaxel for castration-resistant prostate cancer: Results from a phase 1-2 study. Cancer. 2012;118(1):63-71.

13. NCCN [webpage on the Internet]. Clinical Practice Guidelines in Oncology-Prostate Cancer. V1.2012. Fort Washington: National Comprehensive Cancer Network; 2012. Available from: http://www. nccn.org. Accessed March 27, 2012.

14. Horwich A, Parker C, Bangma C, Kataja V; ESMO Guidelines Working Group. Prostate cancer: ESMO Clinical Practice Guidelines for diagnosis, treatment and follow-up. Ann Oncol. 2010;21 Suppl 5: v129-v133.

15. Saad F, Hotte SJ. Guidelines for the management of castrate-resistant prostate cancer. Can Urol Assoc J. 2010;4(6):380-384.

16. Adamo V, Noto L, Franchina T, et al. Emerging targeted therapies for castration-resistant prostate cancer. Front Endocrinol (Lausanne). 2012;3:73.

17. Nelson JB, Fizazi K, Miller K, et al. Phase 3, randomized, placebocontrolled study of zibotentan (ZD4054) in patients with castrationresistant prostate cancer metastatic to bone. Cancer. 2012;118(22): 5709-5718.

18. Scher HI, Jia X, Chi K, et al. Randomized, open-label phase III trial of docetaxel plus high-dose calcitriol versus docetaxel plus prednisone for patients with castration-resistant prostate cancer. J Clin Oncol. 2011;29(16):2191-2198.

19. Regeneron Pharmaceuticals, Inc. Sanofi and Regeneron Announce Regulatory and Clinical Update for ZALTRAP ${ }^{\circledR}$ (Aflibercept) [Press Release]. Tarrytown: Regeneron Pharmaceuticals, Inc; 2012. Available from: http://files.shareholder.com/downloads/ REGN/0x0x557779/94df2942-a7b5-4ea1-9c17-5ba3bd98c198/ REGN_News_2012_4_5_General_Releases.pdf. Accessed December 6, 2012.
Cancer Management and Research

\section{Publish your work in this journal}

Cancer Management and Research is an international, peer-reviewed open access journal focusing on cancer research and the optimal use of preventative and integrated treatment interventions to achieve improved outcomes, enhanced survival and quality of life for the cancer patient. The journal welcomes original research, clinical \& epidemiological

\section{Dovepress}

studies, reviews \& evaluations, guidelines, expert opinion \& commentary, case reports \& extended reports. The manuscript management system is completely online and includes a very quick and fair peerreview system, which is all easy to use. Visit http://www.dovepress.com/ testimonials.php to read real quotes from published authors. 